\title{
Optimization of Sowing Dates and Seeding Rates with Adaptive Control of The Technology of Cultivation of Winter Barley Varieties Mavlono
}

\author{
Zulayho Yarkulova, Abbos Kadirov
}

\begin{abstract}
One of the determining periods in the life of winter cereal plants is sowing (autumn). Only under the condition of good moisture supply and at optimal air temperature, timely and high-quality seedlings can be obtained, tillering shoots and processes of verbalization and hardening of plants to be formed. Based on the importance of the foregoing, this work presents the results of studies in bright gray-earth soils of the Kashkadarya region of the reaction of winter barley of the Mavlono variety for different periods of sowing and seed sowing rate. It was found that plant survival ranged from 86.0 to $89.9 \%$. No significant differences in wintering of plants between crops of different sowing dates were revealed. Seeding rates did not significantly affect the height of plants, spike length and the number of grains in it, which confirms the high plasticity of winter wheat of the Mavlono variety. Our studies have shown that for winter barley of the Mavlono variety in the conditions of the Kashkadarya region, the sowing season is favorable - from 15 October to 1 November, with an optimum sowing rate of 4 million pcs / ha.
\end{abstract}

Keywords: Winter Barley, Dates of Sowing, Seeding Rate, Variety, Yield.

\section{INTRODUCTION}

In modern conditions, it is possible to increase the efficiency of grain production using the cheapest and most affordable means - a variety. Possessing a complex of biological and economically valuable properties, it provides natural and climatic resistance of plants: winter hardiness, resistance to drought, diseases and pests, serves as a biological foundation on which all the main elements of technology are built. [5] - [9]

The efficiency of the use of agricultural crops in production largely depends on the level and timeliness of the development of technology for its cultivation for specific conditions. New varieties of winter barley require

Manuscript received on 09 April 2021 | Revised Manuscript received on 14 April 2021| Manuscript Accepted on 15 May 2021 | Manuscript published on 30 May 2021.

* Correspondence Author

Zulayho Yarkulova*, Department of Biology, Bukhara State University, Bukhara, Uzbekistan. Email: mamatov.tulkin@mail.ru

Abbos Kadirov, Department of Biology, Bukhara State University, Bukhara, Uzbekistan. Email: mamatov.tulkin@mail.ru

(c) The Authors. Published by Lattice Science Publication (LSP). This is an open access article under the CC BY-NC-ND license (http://creativecommons.org/licenses/by-nc-nd/4.0/) adjustments of both individual elements of agricultural technology (timing and methods of sowing, seeding rates, predecessors, quality of seed, etc.), and cultivation technology in general. This problem is especially relevant in years of insufficient moisture, when sowing dates and seeding rates are of decisive importance to obtain high yields of winter barley. The seeding rate becomes an effective method for the formation of the optimal density of productive stalk and is differentiated depending on the variety type, purpose of crops, sowing time, soil moisture, level of mineral nutrition and predecessor. To stabilize the production of winter grain crops in the future, it is necessary to revise and determine the optimal sowing time, taking into account changes in the weather during the sowing period until the termination of the autumn vegetation of plants, inclusive.The purpose of the work is to study various techniques of cultivation of winter barley of the Mavlono variety in the conditions of the Kashkadarya region. The research tasks included: to establish the optimal sowing time and seeding rate of the studied variety; determine the influence of sowing dates and different densities on the formation of elements of productivity and winter hardiness of the plant. His is an International reputed journal that published research articles globally. All accepted papers should be formatted as per Journal Template. Be sure that Each author profile (min 100 word) along with photo should be included in the final paper/camera ready submission. It is be sure that contents of the paper are fine and satisfactory. Author (s) can make rectification in the final paper but after the final submission to the journal, rectification is not possible. In the formatted paper, volume no/ issue no will be in the right top corner of the paper. In the case of failure, the papers will be declined from the database of journal and publishing house. It is noted that: 1. Each author profile along with photo (min 100 word) has been included in the final paper. 2. Final paper is prepared as per journal the template. 3. Contents of the paper are fine and satisfactory. Author (s) can make rectification in the final paper but after the final submission to the journal, rectification is not possible.

\section{MATERIALS AND METHODS}

In 2009-2012, field research was carried out on the Mavlono winter barley variety.

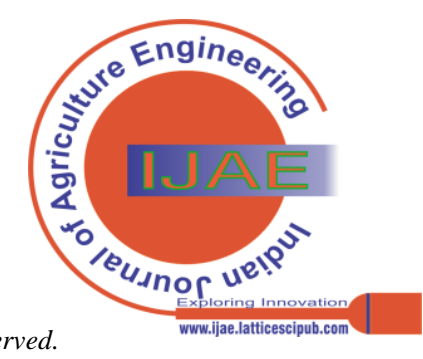


Field experiments were carried out in the fields of the central experimental base of the Kashkadarya branch of the Research Institute of Grain and Legumes in the Karshi District of the Kashkadarya Region in the conditions of irrigated light gray soil.

On the experimental field of the institute, experiments were laid with the sowing dates of winter barley at intervals of fifteen days (October 1, 15 and November 1, 15) and seeding rates with an interval of 0.5 million germinating grains per hectare $(3.0 ; 3.5 ; 4,0$ and 4.5 million). The experiments were carried out in four repetitions on the steam predecessor, the plot area was $10 \mathrm{~m}$. The counts and observations were carried out according to the methodology of the State variety testing of agricultural crops. The meteorological conditions of the years of research differed from each other and from the long-term average. The weather during the growing season of 2009-2012 was characterized by a prolonged drought before sowing, a deficit of precipitation in the autumn growing season, and significant precipitation in the spring months (394 $\mathrm{mm}$ in total). In 2010-2011, the air temperature was higher than the average annual values, about $105.3 \mathrm{~mm}$ of precipitation fell during the growing season, in 2011-2012, the average monthly temperatures were lower than the average annual values, and the rainfall for the entire period was $247 \mathrm{~mm}$. The variety and contrast of weather conditions during the years of research contributed to an objective assessment of the material under study.

Field studies were carried out on light gray soil. Agrochemical indicators: total nitrogen - 0.078; mobile phosphorus - $30 \mathrm{mg}$ / kg, mobile potassium - $380.0 \mathrm{mg} / \mathrm{kg}$.

\section{RESULTS}

Among the indicators that integrate many factors and affect the yield of winter barley is the survival rate of plants to harvest. With a low survival rate, the seeding structure develops spontaneously. Therefore, to ensure a given density, losses of winter barley should be no more than $28 \%$ [1].

In our studies (Table 1 ), the survival rate (the ratio of the number of plants obtained to the number of germinating seeds) ranged from 61.9 ... 73.5\%. It should be noted that this indicator has a tendency to decrease from early to late sowing of winter barley. There were no significant differences in the overwintering of plants between crops of different dates.

This journal uses double-blind review process, which means that both the reviewer (s) and author (s) identities concealed from the reviewers, and vice versa, throughout the review process. All submitted manuscripts are reviewed by three reviewer one from India and rest two from overseas. There should be proper comments of the reviewers for the purpose of acceptance/ rejection. There should be minimum 01 to 02 week time window for it.
Table 1: Characteristics of survival and productivity elements of the Mavlono variety depending on the sowing time (average 2009-2012)

\begin{tabular}{|c|c|c|c|c|c|c|c|}
\hline 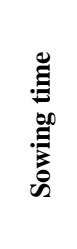 & के & 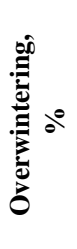 & 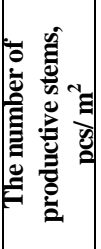 & 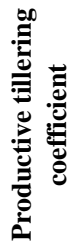 & 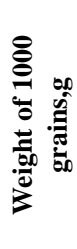 & 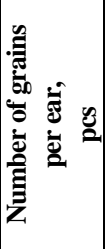 & 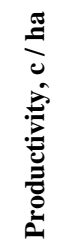 \\
\hline 01.10 & 61,4 & 86,9 & 450 & 3,1 & 40,7 & 32,2 & 42,6 \\
\hline 15.10 & 72,5 & 91,3 & 508 & 3,9 & 43,4 & 36,1 & 52,7 \\
\hline 01.11 & 70,7 & 90,3 & 482 & 3,3 & 41,2 & 35,4 & 44,6 \\
\hline 15.11 & 69,3 & 86,8 & 470 & 2,8 & 38,1 & 32,0 & 34,9 \\
\hline
\end{tabular}

There is no consensus in the literature regarding the importance of tillering grain loaves. But V.R. Williams, V.E. Pisarev, S.A. Muravyov and others believe that with good tillering, due to the growth of the leaf surface, a large amount of organic matter is produced for grain formation. Under favorable conditions, lateral stalks give $30 \ldots 50 \%$ of the grain yield. [2]

According to the results of our research, tillering (the number of stems per plant) is in direct proportion to the sowing time. Analysis of the elements of plant productivity shows that the plants sown in the second decade of October have the highest coefficient of productive tillering.

According to O.M. Turaev and S.S. Fatty [4], winter crops tiller to a greater extent at early sowing dates. In our studies, these data are confirmed - the total bushiness of winter barley plants decreases from early to late. This tendency continued for productive tillering. When sowing in the second decade of October, it was $3.4 \ldots 3.1$, and sowing in November reduces it by 1.9 .

The same was revealed by the weight of 1000 grains and the number of grains per ear. And, as a result, the highest yield was at 15 October sowing. Since the greatest influence on the formation of grain yield was exerted by the mass of 1000 grains $(r=0.6)$, the number of grains in an ear $(r=$ $0.66)$, and the coefficient of productive tillering $(r=0.67)$.

It is known that the optimal density of productive stems should be formed either by increasing the density of the plant, or by the intensity of tillering. With the deterioration of the conditions for the development of plants, tillering plays an ever smaller role and an increasing role is played by the density of plants and, consequently, the seeding rate. [3] The yield of winter barley is determined by both the seeding rate and the weather conditions of the growing season. Over the years of research, practically the same yield was obtained with sowing rates of 3.5 ... 4.0 million pcs / ha - 36.0 and 36.3 c / ha, respectively.

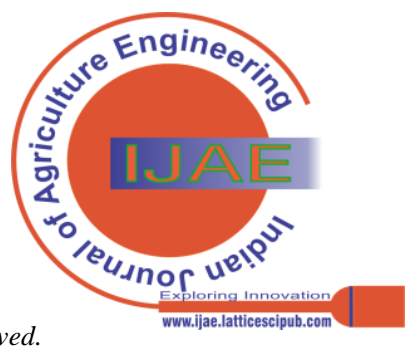


The mass of 1000 grains is a fairly stable varietal trait, which is determined by such a technological method as the seeding rate. It was found that the largest mass of 1000 grains was on thinned sowing - $43.4 \mathrm{~g}$, and the smallest at a rate of 4.5 million pieces / ha - 39.6 g. But this difference is insignificant.

Analyzing the data in Table 2, we can conclude that the seeding rates did not have a significant effect on plant height, ear length and number of grains per ear, which confirms the high plasticity of winter barley variety Mavlono. The maximum indicator of the tillering coefficient was recorded at sowing 4.0 million pcs / ha $-3.4 \mathrm{~g}$.

Table 2: Characteristics of Mavlono winter barley by quantitative traits depending on the seeding rate (average 2009-2012)

\begin{tabular}{|c|c|c|c|c|c|c|c|}
\hline 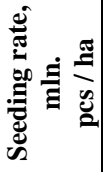 & 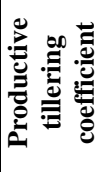 & 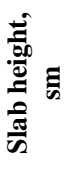 & 㝴 & 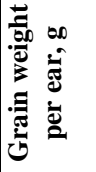 & 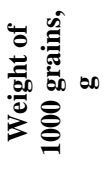 & 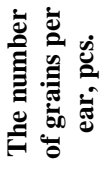 & 总 \\
\hline 3,0 & 3,2 & 95 & 6,7 & 1,29 & 42,3 & 35,7 & 42,6 \\
\hline 3,5 & 2,9 & 94 & 6,8 & 1,32 & 43,4 & 36,0 & 52,7 \\
\hline 4,0 & 3,4 & 97 & 6,9 & 1,30 & 42,1 & 36,3 & 44,6 \\
\hline 4,5 & 3,1 & 96 & 6,5 & 1,28 & 39,6 & 35,3 & 34,9 \\
\hline
\end{tabular}

\section{CONCLUSION}

Thus, for the winter barley of the Mavlono variety in the conditions of the Kashkadarya region, a favorable sowing period is from 10 to 15 October with an optimal seeding rate of 4 million pcs / ha. Plants sown during this period have time to form a developed tillering node, due to this they quickly grow back in spring and are better preserved during the spring growing season.

\section{REFERENCES}

1. N.A. Bohme, Field germination of seeds and survival of barley plants as indicators of adaptation to changing environmental conditions (Russian), Bohme, A. Ya. Bohme, N.V. Tetyannikov // Agrarian Bulletin of the Urals. - 2015. - No. 4 (134). - P. 15-18

2. N.V. Dorofeev, Winter wheat in the Irkutsk region (Russian) / N.V. Dorofeev, A.A. Peshkova, V.K. Voinikov - otv. ed. O.P. Rodchenko. Irkutsk: Art-Press, 2004 .-- 175 p.

3. V.E. Torikov, Sowing rates and terms of grain (Russian)/ V.E. Torikov // Grain crops. - 1993. - No. 1. - P. 26-28.

4. O. M. Turaev, Influence of sowing dates on the yield of winter wheat varieties (Russian) / O.M. Turaev, S.S. Fat // Bulletin of the Mari State University. - 2015. - No. 4 (16) volume 4. - P. 59-61.

5. Z. R. Yarkulova and N. Kh. Khalilov, Influence of the seeding rate and the dose of mineral fertilizers on the yield of autumn sowing barley during irrigation , Bulletin of Michurinsky State Agrarian University No. 2, 2018. P. 95-99

6. Z. Yarkulova, Influence of sowing dates and rates of mineral fertilizers on the yield of winter barley, The latest research in modern science: experience, traditions and innovations: Collected scientific articles of the VII International scientific conference on June 20-21, 2018, North Charleston, SC, USA. - North Charleston, USA:CreateSpace, 2018. p. 65-69.

7. Z. Yarkulova, Influence of timing of crops and norms of mineral fertilizers for winter barley yield, Asian Journal of Science and Technology. Vol.10, Issue,05, May, 2019, pp. 9669-9670. http://www.journalajst.com.

8. Z. Yarkulova and N. Khalilov, Influence of Seeding Norms and Mineral Fertilizer Rate on the yield of Winter Barley, International Journal of Recent Technology and Engineering (IJRTE) ISSN: 2277-3878, Volume-8, Issue- 3S, October 2019 [CrossRef]

\section{AUTHORS PROFILE}

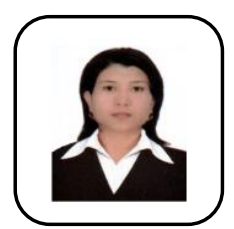

Zulayho Yarkulova. Doctor of Philosophy in Agricultural Sciences, author of more than 30 scientific articles, published 1 monograph on his specialty. 